\title{
Looking Back, Glancing Ahead: State and Federal Legislative Fronts
}

Last year, Congress debated controversial health care legislation and looked at several laws affecting pharmacy and other aspects of patient care. However, all of this debate and study resulted primarily in unresolved issues that will continue to generate arguments and action during 1997.

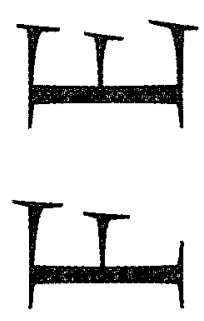

\section{E L A I N E Z A B L O C K I}

ELAINE ZABLOCKI is a health care freelance writer based in Arlington, VA.

Copyright $\odot$ 1997, Academy of Managed Care Pharmacy, Inc. All rights reserved.
M anaged care pharmacy and other health care professionals will be keeping a careful eye on the 105th Congress as members take a renewed look at issues such as entitlement reform. There was lots of talk and some action on the restructuring of Medicaid and Medicare and other issues in the last Congress, but little made it into the books. There will be more talk in this session, but will there be more action?

1996: LOTS OF TALK, LESS ACTION

During 1996, there was lots of activity. But campaigning and other election year activities seemed to prevent any real action from taking place. One of the few instances of decisive action was a plan for restructuring Medicaid as a block grant program, which passed both houses of Congress last year but was vetoed by President Clinton. The

Continued on page 128 
veto was welcomed by many, including pharmacist organizations, who were concerned that under such a program, federal standards for pharmacy reimbursement would be eliminated. There also was concern that tight funds would cause states to limit or eliminate prescription drug benefits.

At the same time, Congress hotly debated a variety of cost-cutting proposals for Medicare but failed to pass any. Generally speaking, these proposals would have permitted delivery of Medicare benefits by private managed care organizations using capitated payments. Organizations representing pharmacists were concerned about potential reimbursement levels under these proposals, and a possible focus on drug distribution rather than pharmaceutical care services.

\section{OTHER ISSUES: DEBATE BUT NO ACTION}

There was substantial bipartisan support for proposals to reform the mission, structure, and operations of the U.S. Food and Drug Administration. (FDA). Major FDA reform legislation was introduced and continually amended throughout the 104th Congress. The original focus of the FDA reform bill was an effort to streamline the approval process for new medications. However, additional issues were attached to the bill throughout the session, including a provision allowing manufacturers to offer providers information about off-label uses of medications under certain conditions. Another provision specifically preserved the right of pharmacists to retain compounding privileges within pharmacy walls. It became clear during the last two weeks:before Congress adjourned that the final compromise proposal on FDA reform would not pass.

Another issue before the 104th Congress was the need for confidentiality and privacy of medical records. The
Medical Records Confidentiality Act, introduced by Sen. Bennett (R-UT) gave patients authority to inspect health information about themselves, required health providers to protect the confidentiality of medical records, and established federal health information privacy protection standards. Similar bills were introduced in the House. However, the legislation did not progress in either place.

Despite the stall, managed care pharmacists should watch this issue carefully in the coming months. Such legislation potentially could be used to limit managed care providers' access to electronically-transmitted prescription information. In June, AMCP: released a position paper that said, "The use of electronic prescriptions benefits patients, prescribers and pharmacists. It's the patient, however, who benefits most by being assured of an error-free prescription for which payment already has been authorized under a prescription benefit plan... Electronic data is consistent, legible, accessible, and easily stored and analyzed. It decreases prescribing errors caused by illegible handwriting, misspelling, and the use of inappropriate abbreviations... Electronic prescriptions also help in the area of formulary administration, which managed care organizations use for,improving patient outcomes and decreasing patient drug costs."

While no specific action was taken on any patient confidentiality bills, the issue was addressed indirectly in the Health Insurance Portability and Accountability Act (informally known as the Kennedy-Kassebaum Bill), which was enacted in August. It provided for the development of standards for privacy . protection for health information, including regulations to assure the confidentiality and integrity of medical records.

The Safe Medications for the Elderly Act was introduced by Rep. Pallone (D-NJ) in 1996. This legislation is ex- pected to receive some attention from the 105 th Congress. It would reimburse pharmacists for providing specified pharmaceutical care services, or "cognitive services," to beneficiaries under Medicare Part B. Covered services include a consultation with a patient that achieves improved drug regimen compliance; a consultation with a physician that results in initiation or discontinuation of drug therapy or change in drug regimen or dosage; and administration of influenza, pneumococcal, and hepatitis $B$ vaccines. Improved compliance must be proven and documented.

\section{MEDGUIDE: TO CHANGE OR NOT TO CHANGE?}

In August 1995, the FDA proposed a rule, known as MedGuide, mandating the development of standardized FDAapproved leaflets to be given to patients whenever they received new prescription drugs. Essentially every pharmacy organization and the pharmaceutical industry expressed concern that focusing too much effort on these could take attention away from more effective methods of patient education. AMCP issued a position statement saying, "The content of printed drug information is currently determined by those pharmacisis who purchase and distribute prescription drugs. The detail of the information supplied is tailored to the needs of the pharmacy's patient population and community practice. If the federal government determined the content of a patient drug information insert, it would interfere with the professional judgment of the pharmacist in giving information to patients with whom he or she is familiar... [MedGuide] would displace the existing system which has not been determined to be inadequate."

As a result of concerns expressed about MedGuide, compromise legisla-

Continued on page 131 
tion was enacted in August 1996. This delayed the proposed FDA MedGuide regulations and required FDA to consider private sector initiatives for alternative written and oral communications. The stated goal of the compromise language is to ensure that $75 \%$ of people who receive new prescriptions will receive written information by the year 2000 , and $95 \%$ by 2006 .

In response to the legislation, the Department of Health and Human Services (HHS) asked an outside party to convene a special steering committee comprised of consumers and representatives from national pharmacy organizations, medical groups, voluntary health care organizations, patient-information database companies, and the pharmaceutical industry to draft a private-sector alternative to MedGuide aimed at giving more useful prescription information to consumers.

The 34-member committee spent weeks working on a compromise plan, which was submitted to HHS Secretary Donna Shalala in December. In January, she announced acceptance of the plan, meaning the government will not intervene for now in private-sector efforts to give consumers more useful prescription information. Pharmacy organizations and others are expected to take new initiatives in this area. Meanwhile, FDA will continue to do surveys to measure how frequently consumers report getting useful information, and launch new surveys to gauge the quality of the information being provided.

\section{STATES CONSIDER HEALTH CARE ISSUES}

In addition to lederal legislation, increasing activity at the state level has the potential to dramatically reshape the health care environment. For example, during 1996, 15 states considered bills on drug pricing that would require pharmaceutical manufacturers to offer the same terms to all nonretail buyers. Legislation to this effect passed in Maine in 1996. As of mid-February 1997, Mississippi had introduced a bill requiring drug manufacturers. to offer the same discounts to all classes of purchasers (HB1275). Observers plan to watch the following states for possible developments on this front: Pennsylvania, Connecticut, North Carolina, South Carolina, Kentucky, Louisiana, Ohio, Maryland, Minnesota, Montana, New Mexico, and Oregon.

Many states also have considered "any willing provider" legislation that requires health plans to accept any provider willing to meet the standard contracting terms and conditions of the health care network. Wisconsin passed "any willing pharmacy" legislation in 1989. At present, 24 states have enacted some form of this legislation, with 11 states passing laws that only apply to pharmacy.

Since federal Medicaid reform has stalled, many states have applied for waivers from the Health Care Financing Administration (HCFA) so they can implement their own Medicaid managed care systems. At present, 10 states have received and implemented Section 1115 Medicaid waivers (which permit five-year demonstration projects), six have received approval and are awaiting implementation, more than 12 have applications pending for the waivers, and several more are now drafting their applications. Key issues are whether pharmacy services will be covered through managed care or carved out and not covered under the capitated payments system.

Elsewhere, in Oregon voters last year considered a ballot initiative that would have banned capitated payments for health care providers. The measure failed at the ballot box. And eight states considered some form of payment to pharmacists for cognitive services, with legislation passing in six states. New Jersey, Oklahoma, and West Virginia passed laws requiring insurers to reimburse registered pharmacists for providing diabetes self-management services. Meanwhile, Mississippi passed a law au- thorizing Medicaid reimbursement for additional pharmacist services including monitoring the initiation of drug therapy, changes in the form or dosage of outpatient medications, and administration of vaccines.

In addition, the National Association of Boards of Pharmacy (NABP) approved model rules on electronic transmission of prescriptions in Spring 1996, that prohibit access by pharmacy benefit managers during transmission of any prescription from prescriber to provider. These model rules probably will encourage individual states and state pharmacy boards to enact this restrictive legislation.

State executive agencies, as well as state legislatures, are considering measures that could substantially affect pharmacists and other health care professionals. For example, the Texas Department of Insurance and the California Department of Corporations are both considering action to limit the use of closed formularies.

\section{NEW CONGRESS TO REFORM MEDICARE AND REVISIT CONTESTED ISSUES}

While it is impossible to predict the exact course of the 105th Congress, it is clear that certain major issues will be considered early in the legislative process. Medicare reform is certain to head the 1997 legislative agenda, since under current projections the Part A Trust Fund will become insolvent by the year 2001 . The debate over Medicare is likely to include long-term structural issues as well as short-term cost-cutting, including substantial cuts in Medicare payments to HMOs, cuts that would probably force plans to cut back their offers of prescription benefits to seniors. Medicaid reform will be on the table again. And FDA reform, since it came so close to passage last year, will likely be refought early in the 105th Congress.

Another issue with significant poten-

Continued on page 134 
tial impact on all health care providers is the continuing debate over privacy and confidentiality of medical records. One expected proposal will redraft confidentiality legislation to allow health professionals continued access to the patient medical information they need, and also allow them to implement appropriate safeguards to preserve confidentiality of records.

In addition to these broad issues, which have implications for the entire field of health care, we also can expect continuing debate on more focused issues of special concern to managed care pharmacists, including legislation to reimburse pharmacists for providing cognitive pharmaceutical care services to Medicare patients.

On the state front, formularies are likely to receive some attention, especially after the March 1996 publication of the controversial Susan Horn study. The study, which found a correlation among restrictive formularies, higher health care costs, and greater use of medical services, has sparked a debate over closed formularies. And although the study has come under criticism from many sources, states are likely to debate the formulary issue in a variety of forums. As of mid-February 1997, Georgia, Ohio, and Tennessee had introduced managed care consumer protection bills that would undermine formularies by requiring plans to cover all FDA-approved drugs. In Virginia, the legislature this year is considering a bill that would ban therapeutic substitution where any financial incentive is involved

Because of increasing activity on the state level on a wide range of health care issues, many professional associations are expanding their level of staff and member volunteer commitment to monitor actions of state legislatures and agencies. These efforts promise to keep everyone involved in health care, including managed care pharmacy, busy in the coming months.

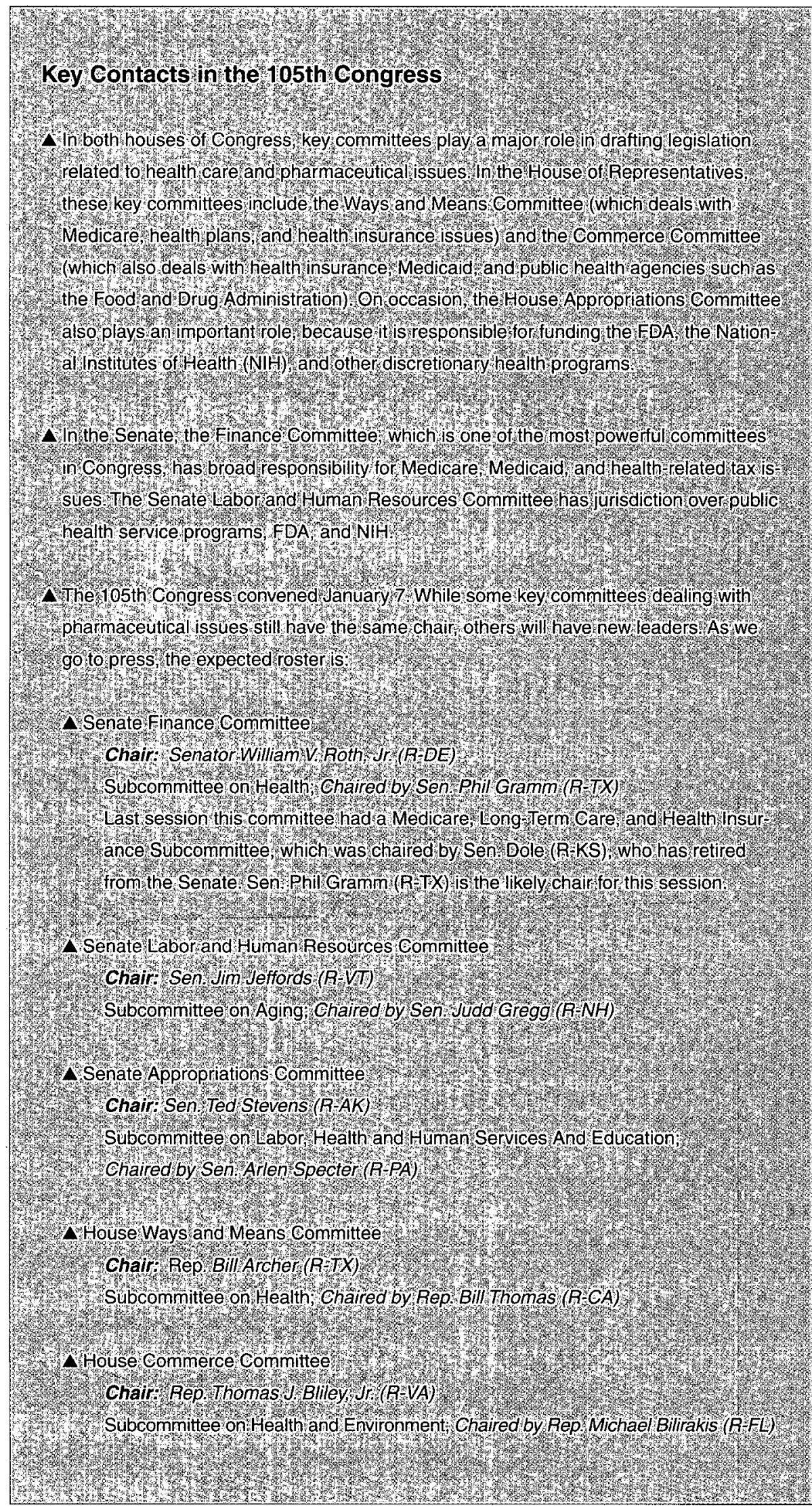

